\title{
Transesophageal endoscopic ultrasound (EUS) in pulmonary medicine
}

\author{
Micaela Romagnoli \\ Carlo Gurioli \\ Venerino Poletti
}

Pulmonology Unit, Department of Thoracic Diseases, "Morgagni-Pierantoni" Hospital, Forlì, Italy

\author{
Address for correspondence: \\ Micaela Romagnoli, MD, PhD \\ Pulmonology Unit, Department of Thoracic Diseases \\ "Morgagni GB-Pierantoni" Hospital \\ Via C. Forlanini, 34 - 47121 Forlì, Italy \\ Phone: +39 0543735042 - Fax: +390543 738668 \\ E-mail: m.romagnoli@ausl.fo.it
}

\section{Summary}

Endoscopic ultrasound (EUS) is a safe and minimally invasive procedure, allowing ultrasound-guided needle aspirates in real-time, with high-sensitivity diagnostics. EUS is an instrument available to the pulmonologist for the diagnosis of mediastinal neoplasms, benign and malignant, including the mediastinal lymph node staging of non-small cell lung cancer (NSCLC), with a specific sensitivity up to $90 \%$. EUS allows to detect and to sample even small lesions with a diameter of $3 \mathrm{~mm}$, which are not visible at usual imaging.

The most recent guidelines on mediastinal nodal staging of lung cancer report endoscopic and transbronchial ultrasound (EUS and EBUS) as a viable and valid minimally invasive alternative to the "classical" surgical staging with mediastinoscopy, resulting in significant savings in diagnostic invasive surgical procedures, and unnecessary thoracotomy, with a consequent high economical impact. EUSFNA, as EBUS-TBNA, has been shown to be able to give in one time the diagnosis, the typing, staging, and genotyping of lung cancer with a single diagnostic procedure. However, it must be highlighted that in the mediastinal nodal re-staging of NSCLC, the sensitivity of EUS-FNA significantly decreases, being $<50 \%$. Therefore, in all cases of negativity at the re-staging a surgical mediastinoscopy should be performed before therapeutical decisions.

EUS should be performed in referral centres, so patients should be referred to centres of reference for a complete endoscopic staging with EBUS/ EUS. All patients, except those with a known pathologic esophageal stenosis, might be investigated by EUS, even on an outpatient basis, in mild sedation with midazolam, or deep sedation with anaesthesia care based on the internal structure organization, and complications are very rare.

KEY WORDS: EUS, lung cancer, endoscopy ultrasound, mediastinal lymph node, staging, FNA, TBNA, bronchoscopy.

\section{Introduction}

Transesophageal endoscopic ultrasound, known by its acronym from the English language "EUS" (endoscopic ultrasound), is an increasingly available diagnostic and therapeutic tool with potential wide applications, both in the gastrointestinal tract and in the mediastinum.

Endoscopic ultrasound with radial probe was developed in the 1980s for gastrointestinal procedures, but the use of EUS by pulmonologists is quite recent, due to the advent of EUS using linear echoendoscopes a decade later. In particular, the ability to sample lymph nodes and suspected malignancies by fine needle aspiration (FNA) led to its wider EUS is an effective and safe procedure available to pulmonologist for the study of the mediastinum, although it was initially developed in the field of gastroenterology as method for the assessment of the pancreas.

uptake, although service provi-

sion still remains centralised in most areas.

The mediastinum, due to its central location in the chest, can be easily navigated mostly (middle and posterior mediastinum) by EUS. This method is an effective and safe procedure available to pulmonologists for the study of the mediastinum, although it was initially developed in the field of gastroenterology as method for the assessment of the pancreas (1).

It was in 1996 that the use of EUS was proposed for the first time as a diagnostic method for mediastinal lesions of unknown etiology (2). The first studies on EUS for the typing of mediastinal lesions were often conducted by gastroenterologists, who first used the EUS with radial probe for a paraesophageal 360 degrees viewing, to pass then, once the suspected lesion was identified, to the linear probe for ultrasound-guided fine needle aspiration in real time $(3,4)$. As the sonographic criteria of lymph node lesions, such as shape, size, pattern and demarcation ultrasound, do not differentiate between benign and malignant lesions, it is necessary to sample such lesions when visible, taking into 
account that even small lymph nodes (e.g. $4 \mathrm{~mm}$ ) might be sampled (5).

Currently, the EUS is becoming more and more a common procedure in the hands of pulmonologists for the diagnosis of central pulmonary neoplasms adjacent to the esophagus, for the mediastinal staging (and restaging) of lung cancer, as well as for the diagnosis of mediastinal lymph node granulomatous diseases, such as sarcoidosis and tuberculosis.

\section{Transesophageal ultrasound anatomy of the medi- astinum}

Within the esophageal lumen there are no landmarks for orientation. Therefore, the investigation with EUS is guided by ultrasound images, and the detection of various anatomical structures is mainly based on the relationship with the structures identified cardio-vascular ultrasound. The limits of ultrasound for the detection of mediastinal lymph node stations are based on the classification of the new map of the mediastinal lymph nodes of the IASLC $2009(6,7)$.

Transesophageal endoscopic ultrasound is performed with a linear echoendoscope (Figure 1), consisting of an endoscope equipped with an ultrasound transducer at its distal proximity, which gives a real-time viewing, with a scanning angle variable from 120 to $180^{\circ}$, with the possibility of colour Doppler viewing for the identification of vascular structures.

EUS can be performed as an outpatient basis with mild sedation with intravenous midazolam, or with deep sedation with anaesthesia care in relation to the usual "settings" of the various operating units, always with the patient lying on his left side. The duration of the procedure is about 20-30 minutes, including ultrasound-guided fine needle aspirations, the so-called EUS-FNA (endoscopic ultrasound fine-needle aspiration).

The echo-endoscope is introduced through the mouth

(through the use of a mouth-

The limits of ultrasound for the detection of mediastinal lymph node stations are based on the classification of the new map of the mediastinal lymph nodes of the IASLC 2009. piece), and pushed gently until the gastric wall can be sonographically individualized, and the left hepatic lobe, which presents cranially the hepatic vein flowing into the inferior vena cava, can be depicted. Proceeding to the caudal direction, as well as the diaphragm, within the body of the stomach, oriented posteriorly on the left, the spleen can be located, and left kidney, and immediately above, the left adrenal gland, which can also be sampled with EUS- FNA.

Proceeding proximally to the left hepatic lobe, the inferior vena cava can be identified, which empties in the right atrium, and between it and the liver the diaphragm can be recognized. At this level lymph nodes station 9 (of inferior pulmonary ligament) can be identified. Just above it, always moving towards the mouth,

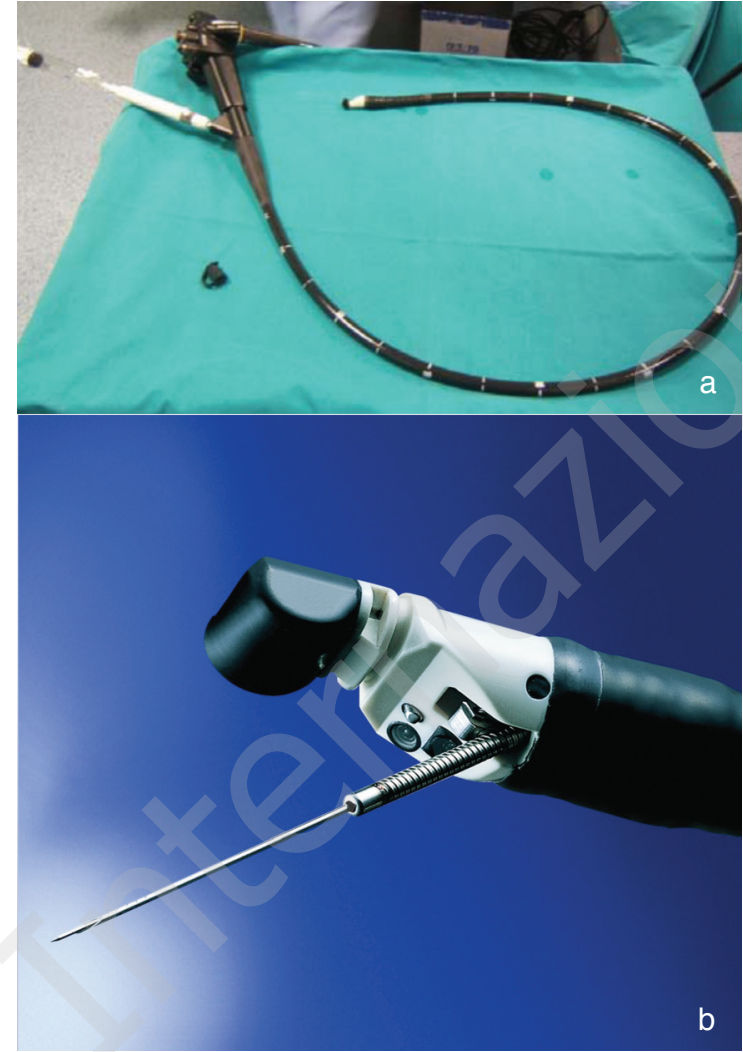

Figure $1 \mathrm{a}, \mathrm{b}$ - Transesophageal endoscopic ultrasound (EUS) (a), and EUS with linear probe with 22-gauge needle (b).

oriented posteriorly and to the right the azygos vein and the vertebral column will display, while posteriorly on the left there is the descending aorta.

Going back again, orienting the front and slightly to the left, there is the bulb with aortic semilunar valves and the mitral valve, left atrium, right pulmonary artery at its origin, the left ventricle and the ascending aorta. The lymph nodes of station 8 (para-esophageal), when visible, are located along the left atrium. On top of the left atrium, one can identify the lymph nodes of station 7 (subcarinal) between the left atrium, pulmonary artery and right ascending aorta. When present, the lymphadenopathy in the $4 \mathrm{~L}$ is between the right pulmonary artery and the ascending aorta, and more sideways lymph nodes station 5 (aorto-pulmonary), separated by $4 \mathrm{~L}$ from the aorto-pulmonary ligament (Figure 2). The lymph nodes of station 6 (para-aortic) are located laterally to the ascending aorta and aortic arch, between the planes through the top and bottom edges of the aortic arch. Station 6 can also have an approach with EUS- FNA, consisting in a trans-aortic FNA, that must be unique, in one-step (8). More difficult is the visualization of para-tracheal upper left $(2 \mathrm{~L})$ lymph nodes, and especially of the right para-tracheal ( $2 R$ and $4 R$ ), due to the interposition of air in the trachea and bronchi. 


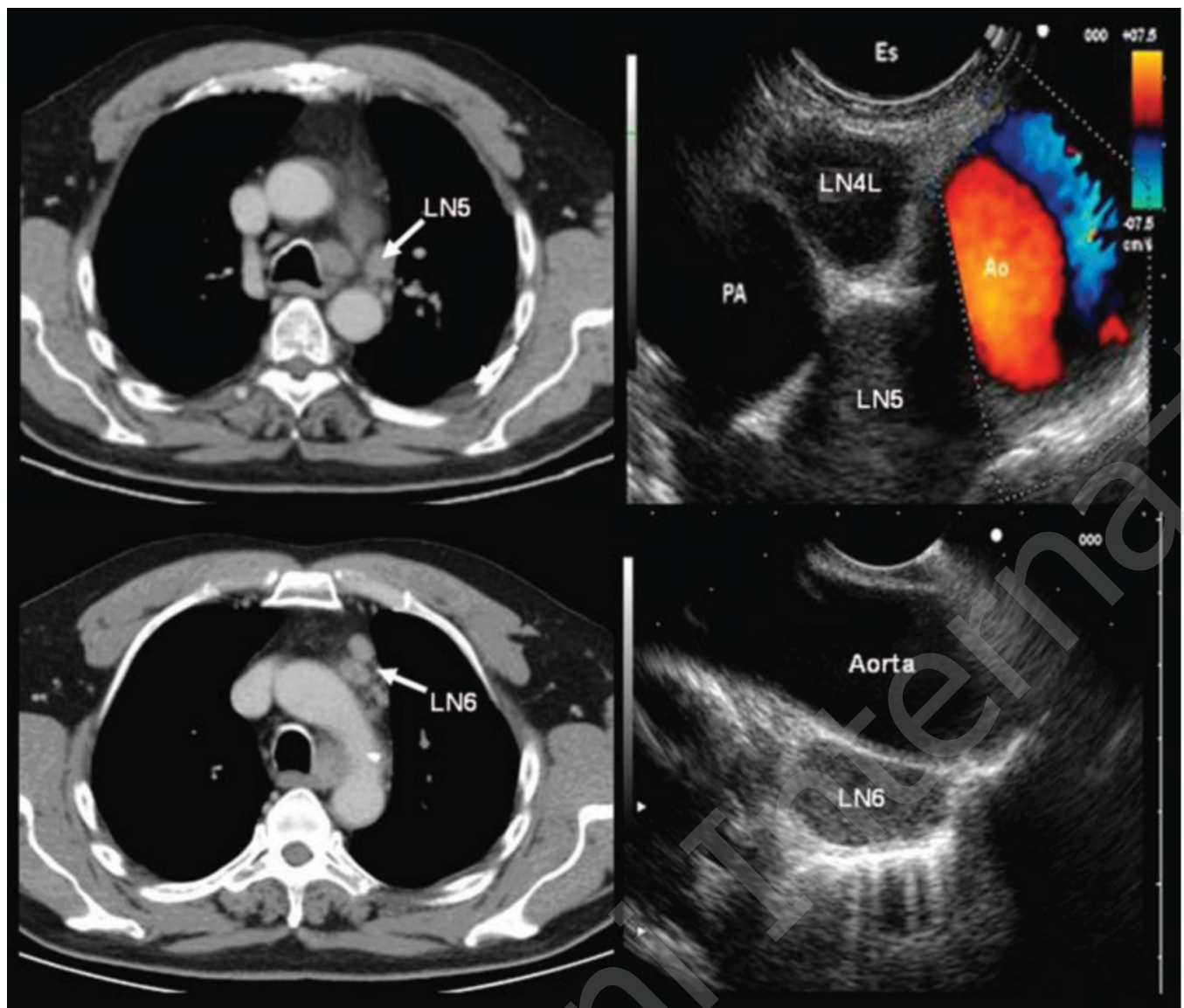

Figure 2 - Chest CT scan and EUS images of $4 \mathrm{~L}$ adenopathy, between the right pulmonary artery and ascendant aorta; adenopathy 5 (aortic-pulmonary window), separated from station $4 \mathrm{~L}$ by aortic-pulmonary ligament; and station 6 .

\section{Endoscopic ultrasound-guided fine needle aspira- tion (EUS-FNA)}

EUS is able to provide the pulmonologist an ultrasound guidance for needle aspirates (fine needle aspiration, FNA) in real time, of lesions in the posterior and medium mediastinum, and lymph node stations accessible, through the introduction in the operating channel of the echo-endoscope of a needle 22 - gauge (also available needles 19 and 25 - gauge, though not used, and the

EUS is able to provi-
de an ultrasound
guidance for needle
aspirates in real ti-
me, of lesions in the
posterior and me-
dium mediastinum,
and lymph node sta-
tions accessible,
through the intro-
duction in the opera-
ting channel of the
echo-endoscope of
a needle 22 - gauge
placed in suction.
use of which is not supported by the data in the literature), placed in suction. After the execution of 5-6 aspirations and removal of the needle from the operating channel, via a $10 \mathrm{ml}$ syringe air is forced through the needle of the sampling just executed, so that expels the sample aspirated onto glass slides. On average, a fine needle aspiration is able to obtain two direct smears - a slide is dried with 0.95 alcohol for cytological analysis per- formed by the pathologists, while the other is stained with Diff Quick for the so-called ROSE (rapid-on-site examination), extemporaneous examination that serves to verify in real time whether the material obtained is representative (9). In addition, samples may be streaked onto slides and directly included in paraformaldehyde, to obtain the so-called cell-blocks.

Although there are no pathognomonic sonographic signs indicating lymph node for benign or malignant, the lymph nodes with short axis $>1 \mathrm{~cm}$, with crisp edges and diffuse hypoechoic are most likely to contain metastases.

The lymph nodes that need to be firstly sampled are those contralateral (N3) to the primary lesion, i.e. those for which, if positive, you have the worst staging, before analyzing the lymph nodes in the N2.

\section{Training for EUS}

The evidence that EUS is an important method for the typing of mediastinal lesions are more and more convincing, so much so that this procedure was included in the recent guidelines on the staging of lung cancer $(10,11)$. Therefore, it is now the task of the pulmonary international community to implement and disseminate 
the use of EUS to the pulmonologist, as a specialist in diseases of the chest, and therefore responsible for the application of the methods currently available, and for the most advanced for the diagnosis and best therapeutic approach. In particular, pulmonologists are the experts of lung cancer, and therefore they represent the most suitable doctors in the integration of all clinical information (12).

How do we learn to use EUS? Based on this question, a study was recently conducted in the Netherlands on the training and implementation of EUS for the diagnosis and staging of lung cancer. The study involved five hospitals, including four national pulmonology implementation centers and one expert centre. The study was preceded by an initial phase of oral presentations during meetings in order to give information on indications and usefulness of the method to pulmonologists and thoracic surgeons (13). The training included nine doctors, seven pulmonologists without any knowledge of endobronchial (EBUS) or transthoracic ultrasound, or transesophageal procedures, and two gastroenterologists already experts on radial and linear EUS for gastroenterological indications (75 procedures each), but without experience of use of this method for the staging of lung cancer. Before specific training, the seven pulmonologists learned by gastroenterologists of their hospitals to introduce the gastroscope in twenty-five patients. The training included a full day of oral presentations in the expert centre, and sixteen practical learning sessions in the expert center, one day a week, with EUS procedures performed in 3 patients per session.

After the first 12 sessions, doctors began to perform EUS in the hospitals where they were regularly working. Subsequently, four other sessions were performed in the expert center, at a distance of 9-12 months from the initial use of this technique in their respective hospitals, for a total of 50 EUS procedures per physician assisted by experts. The results of this study, which enrolled 551 patients for staging of lung cancer with EUS, showed that physicians who participate to a program of implementation achieved a sensitivity and diagnostic accuracy not statistically different compared to experienced centers ( $83 \%$ vs $82 \%$ and $89 \%$ vs $88 \%$ ) (13).

\section{Indications and contraindications}

The indications to perform EUS are mainly represented by: a) diagnosis/staging of mediastinal lymphadenopathy in EUS-accessible stations (station 4L, $5,6,7,8$ and 9 ) in patients with or suspected carcinoma of the lung or extra-thoracic malignancies, b) diagnosis of mediastinal or intrapulmonary masses in anatomical contiguity to the esophagus, c) liver or d) suspected left adrenal metastases of lung carcinoma or of extra- thoracic malignancies. The most frequent indication for the pulmonologist is represented by mediastinal diagnosis/staging (and re-staging) of lung cancer, but also diagnosis of mediastinal benign diseases, which are not infrequent, as it will be later described.
EUS-FNA might represent the first diafor mediastinal lesions of the middle and posterior mediastinum, and/or in cases of patients with severely compromised lung function who cannot tolerate bronchoscopic procedures. gnostic approach

EUS-FNA might represent the first diagnostic approach for mediastinal lesions of the middle and posterior mediastinum, and/or in cases of patients with severely compromised lung function who cannot tolerate bronchoscopic procedures. For lesions of the anterior and superior mediastinum the approach with bronchoscopy with EBUSTBNA, or CT-guided fineneedle aspiration is more appropriate. Obviously, in centres where neither EUS nor EBUS methods are available, the diagnosis is still performed with invasive procedures such as mediastinoscopy and surgical thoracoscopy. In patients with suspected lung cancer and presence of mediastinal lymphadenopathy on CT scan, evidence of tissue invasion neoplastic lymph nodes is essential for the diagnosis and staging of the disease at the same time, by the mean of a single procedure, with a strong impact on invasive surgical staging. Thus, in case of positivity for mediastinal metastases at EUS-FNA surgery is not required, with obvious effects on costs, invasiveness and possible complications (14). EUSFNA might also be used in some cases for staging of distant metastasis (M1), as in
Another indication of EUS-FNA is the diagnosis of mediastinal masses and benign granulomatous Iymphadenopathy, e.g. tubercolosis, and sarcoidosis, with a sensitivity in the detection of lymph nodal nonnecrotizing granulomas of about $87 \%$. the presence of suspected metastases to the left lobe of the liver and/or to the left adrenal gland (15). Further indications to EUS-FNA are represented by the presence of pulmonary lesions adjacent to the esophagus $(8,16-$ 18). More difficult is the diagnosis with EUS-FNA of mediastinal lymphoproliferative processes, because of the frequent need in these cases for histological samples obtained by extensive surgical techniques (19).

Another indication of EUS-FNA is the diagnosis of mediastinal masses and benign granulomatous lymphadenopathy, e.g. tuberculosis (20-22), and sarcoidosis, with a sensitivity in the detection of lymph nodal non-necrotizing granulomas of about $87 \%$ (23).

The contraindications to EUS-FNA are fundamentally represented by a status of known current bleeding or obstruction of the esophagus, and the suspicion that the lesion to be sampled is a cystic lesion, because of the high risk of infection and mediastinitis in these cases $(24,25)$. Therefore, if the lesion is anechoic under ultrasound visualization, with a suspicious of liquid contents, then it should not be sampled with FNA.

\section{EUS-FNA for the diagnosis of neoplastic disease}

Mediastinal staging of non-small cell lung cancer 
(NSCLC) certainly represents the most frequent indication to EUS-FNA for pulmonologists. Thus, the treatment of metastatic NSCLC is

The addition of EUS investigation to surgical mediastinoscopy was able to increase the sensitivity for mediastinal lymph node metastases up to $93 \%$, being able to avoid unnecessary thoracotomy in 1 case out of 6 . determined by a careful and accurate staging of the disease, and in case of radiological absence of distant metastasis (M1), the nodal mediastinal staging $(\mathrm{N})$ becomes crucial to the choice of patient's treatment, to settle between surgical approach or chemo/radiotherapy approach. "Tissue is the issue" is the fundamental basis for the mediastinal staging of NSCLC, since it is known that CT/PET scan has a high negative predictive value for mediastinal lymph nodes (although the problem of nodal "micrometastases " remains, and cannot be assessed by this investigation), but has a low positive predictive value, so the tissue sampling becomes crucial in the case of PET positive mediastinal lymphadenopathy. A systematic literature review and meta-analysis published by Micames et al. (26) showed that in lymphadenopathy with a minor axis at chest CT $>1 \mathrm{~cm}$ the sensitivity and specificity of EUS-FNA in nodal staging of NSCLC is of $90 \%$ and $97 \%$ respectively, while the sensitivity is reduced to $58 \%$ when the major nodal axis is $<1 \mathrm{~cm}$.

The most recent guidelines on nodal staging of lung cancer report endoscopic and transbronchial ultrasound (EUS and EBUS) as a viable and valid minimally invasive alternative to the "classical" surgical staging with mediastinoscopy $(10,11)$, with a consequent reduction in the needs for surgical approach up to 2/3 of patients. One of the fundamental studies that provided evidence in this sense, was published by Annema et al. in 2005 , an important work on the impact of the EUS procedure for the mediastinal nodal staging of NSCLC (14). Out of a total number of 242 procedures, this study showed that in $70 \%$ of cases it was possible to avoid surgical procedures, since in $49 \%$ of cases EUSFNA demonstrated a N2 nodal staging, a $8 \%$ was SCLC, $5 \%$ had a T4N2, a T4N0 was shown in $4 \%$, N3 in $3 \%$, and $1 \%$ had a diagnosis of non-malignancy. Moreover, the addition of EUS investigation to surgical mediastinoscopy was able to increase the sensitivity for mediastinal lymph node metastases up to $93 \%$, being able to avoid unnecessary thoracotomy in one case out of 6 (27). Additional findings were published later, confirming the high sensitivity of EUS (93\%) in the mediastinal nodal staging of NSCLC, with no difference as compared to surgical staging (73\%, p =ns) (28).

The study that perhaps represents the most helpful work to clarify the role of ultrasonography (EUS + EBUS) for the mediastinal staging of NSCLC as compared to surgical mediastinoscopy, was the multicentre, randomized ASTER trial, evaluating 241 patients with suspected unresectable NSCLC, as indicated by CT and PET (29). The primary objective of the study was to determine the sensitivity of the 2 methods (EUS + EBUS vs surgical mediastinoscopy) for staging
N2/N3. The patients were divided into 2 arms with a randomization 1:1: A) EUS + EBUS, and if negative surgical mediastinoscopy (arm 1, 123 cases), and B) surgical mediastinoscopy (arm 2, 118 cases). When the samples were positive, patients were sent to chemo/radiotherapy protocols, while all negative cases underwent mediastinoscopy (arm 1) and surgery (arm 1 and arm 2). The final results showed no statistically significant difference of sensitivity for N2/N3 between the two methods, with a sensitivity of $85 \%$ for EBUS+EUS and of $79 \%$ for mediastinoscopy, respectively. However, there was a significant reduction of unnecessary thoracotomies in patients of arm 1 in favour to EUS/EBUS procedure ( $7 \%$ in the EUS + EBUS group vs $18 \%$ in the mediastinoscopy group, $\mathrm{p}=0.02$ ) (29).

\section{Staging of NSCLC in the absence of mediastinal lymphadenopathy at CT and/or CT/PET}

Only few published data are available on EUS-FNA sampling of lymph nodes not enlarged on CT and PET negative, since almost all studies evaluated enlarged lymph nodes. However, in consideration of the issue of known nodal micrometastases in lymph nodes not enlarged at CT and PET negative (which can be as high as $20 \%$ ), there are some very interesting findings published in a retrospective study and a prospective study $(30,31)$. The retrospective study, which included 69 patients with NSCLC in the absence of CT lymphadenopathy, showed at EUS-FNA advanced disease in $25 \%$ of cases, with a sensitivity and specificity of 61 and $98 \%$, respectively (30). In the prospective study, which evaluated 76 patients with NSCLC and absence of mediastinal lymphadenopathy at chest CT, a diagnosis of advanced disease (T4 or N3) was found by EUSFNA in $12 \%$ of cases (31). These data highlight the relative limits of imaging currently available in mediastinal nodal staging of NSCLC, and the need for further prospective studies.

\section{Mediastinal nodal re-staging of NSCLC}

Patients initially NSCLC stage III (N2/N3) who after chemo/radiotherapy become N0, may benefit from surgical treatment, which represents the current therapeutic indication of these selected cases. EUS might be indicated in these patients for mediastinal re-staging after treatment with neo- adju-

vant chemo/radiotherapy. However, the sensitivity and the false-negative rate of EUS-FNA in the mediastinal nodal re-staging of NSCLC stage III still has a few limitations that must be taken into account. In one series of 58 patients with stage III NSCLC with histological evidence of N2/N3, EUS-FNA has detected at the re-staging the persistence of N2/N3 lymph node metastases in 15 patients $(26 \%)$. false-negative rate of EUS-FNA for mediastinal restaging were 44 and $58 \%$, respectively, showing that this procedure is not useful for the exclusion of mediastinal metastases, and surgical re-staging is indicated in the absence of mediastinal metastases at EUS-FNA.
Sensitivity and the 
Of the 43 patients without persistent mediastinal metastases at EUS, 33 patients subsequently underwent surgical verification of the mediastinal nodes in whom persistent metastases (yN2/N3) were found in 19 patients (58\%), and loco-regional downstaging (yN0) was achieved in the other 14 (42\%). The prevalence of persistent nodal metastases in the 48 patients who could be analyzed was $71 \%$. Sensitivity and the false-negative rate of EUS-FNA for mediastinal restaging were 44 and $58 \%$, respectively (32), showing that this procedure is not useful for the exclusion of mediastinal metastases, and surgical re-staging is indicated in the absence of mediastinal metastases at EUS-FNA. Previous data had shown better results, but in a smaller series of patients (19 consecutive patients) and with a lower staging N1-N2 (33). EUS-FNA was used in the re-staging after induction chemotherapy in all 19 patients with NSCLC, and previous evidence of tissue ipsilateral hilar lymph node metastases (N1) or subcarinal (N2). The positive predictive value, negative predictive value, sensitivity, specificity and the diagnostic accuracy of EUS-FNA in the re-staging mediastinal lymph nodes were, $100,67,75,100$ and $83 \%$, respectively (33).

\section{Diagnosis of mediastinal or intrapulmonary mass- es}

EUS-FNA might be used as the method for diagnosis in selected patients with intrapulmonary neoplasms localized in the vicinity of the esophagus (Figure 3 ). A retrospective study published in 2004 (16), including patients with lung masses confined to the parenchyma or extended to the mediastinum who underwent EUSFNA, after a previous non-diagnostic bronchoscopy and/or CT-guided biopsy. In these cases, the diagnostic yield for EUS-FNA was $100 \%$, in the absence of complications. The following year, a prospective study was published (17), which included patients with suspected lung cancer adjacent to or near the esophagus (less than $1 \mathrm{~cm}$ ) already subject to a non-diagnostic bronchoscopy, none of the patients having mediastinal nodal enlargement at the CT scan of the chest. The rationale behind the work was the high percentage of failures diagnostic bronchoscopy in central pulmonary neoplasms (30\%) (34), associated with invasiveness and the risk of complications of alternative methods used in these cases, as CT-guided biopsy with pneumothorax in $25-45 \%$ of cases $(35,36)$. The diagnostic yield obtained was $97 \%$, with no complications. In the
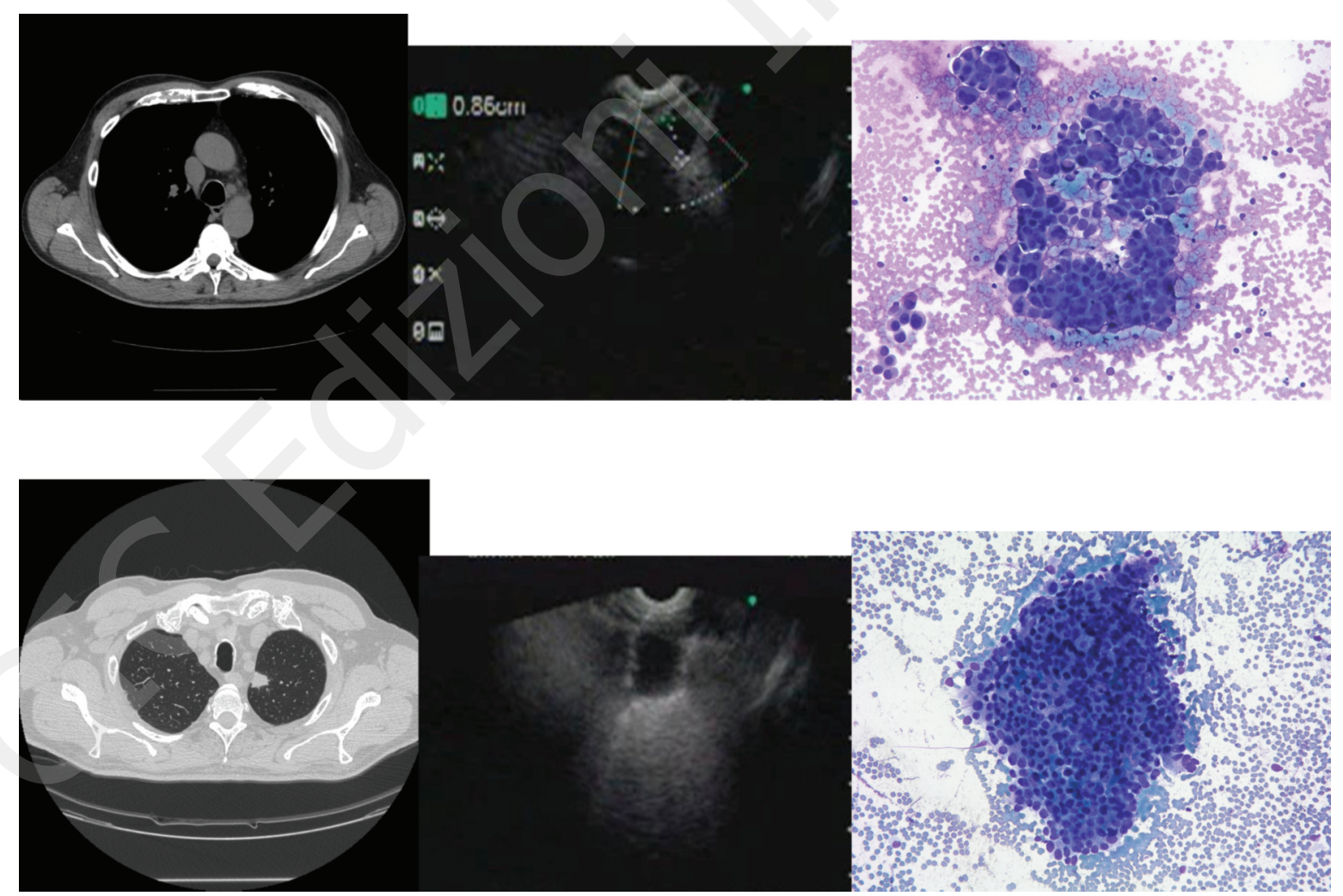

Figure 3 - Patient 74 year-old, male, former smoker, with evidence at chest CT scan of an intra-pulmonary para-mediastinal nodule $(16 \times 19 \mathrm{~mm})$ at the apico-posterior segment of the left upper lobe, and $4 \mathrm{~L}$ adenopathy, both positive at CT/PET scan. At EUS investigation, evidence of left para-tracheal adenopathy $8 \times 8 \mathrm{~mm}(4 \mathrm{~L})$, and of a upper intra-pulmonary left para-tracheal hypo-echogenic area of $16 \times 11 \mathrm{~mm}$, compatible with the left intra-pulmonary para-mediastinal nodule. EUS-FNA performed on both sites (4L adenopathy and intra-pulmonary nodule) documented cancer cells either on the nodule and adenopathy (N2 NSCLC). 
only case of failure diagnosis was a non-Hodgkin lymphoma. In 2006, other authors have proposed EUSFNA in the diagnosis of advanced lung cancer (37). In this prospective study, patients not amenable to surgical treatment were included. The main objective was to evaluate the diagnostic yield of EUS-FNA focused on different structures/organs, pulmonary lesions in the vicinity of the esophagus, mediastinal lymph nodes, liver or left adrenal metastases. In the group of patients in which the lesion was sampled pulmonary diagnostic accuracy was $68 \%$. The sampling of the lung mass in this series resulted in complications in two cases: chest pain resolving spontaneously, and self-limiting haemoptysis. In the 9 patients with massive pulmonary diagnosis was obtained in $77 \%$ of cases (7 of 9 ).

\section{Staging M1 (suspected liver metastases or the left adrenal gland)}

The liver and adrenal glands are privileged sites of metastatic spread in patients with lung cancer. Liver and adrenal metastases were diagnosed by EUS-FNA in a prospective study published in 2008 , demonstrating the high sensitivity of this technique for staging M1 (38). The abdomen CT and PET have a limited positive predictive value for the diagnosis of metastases of the

\section{A recent study sho- wed a sensitivity of $86 \%$ for EUS-FNA in the diagnosis of adrenal metastases.} adrenal glands, respectively $62 \%$ and $81 \%$ (39). Traditional techniques for obtaining tissue samples from the left adrenal gland are the CT guided percutaneous needle aspiration and laparoscopic adrenalectomy, procedures are not free from complications (pneumothorax, bleeding). The left adrenal gland can be seen and sampled in real-time with needle aspiration through the stomach during transesophageal endoscopic ultrasonography (40). A recent study showed a sensitivity of $86 \%$ for EUS- FNA in the diagnosis of adrenal metastases (41). In $29 \%$ of patients surveyed it was benign tissue. The procedure did not cause complications, even though in the literature a case of bleeding after EUS-FNA of the left adrenal gland is described (42).

\section{Applications for research of genetic mutations}

Samples obtained by EBUS-TBNA from metastatic mediastinal lymph nodes in patients with NSCLC might be suitable not only for diagnosis and sub-typing, but also for genetic research somatic mutations in EGFR and K-RAS (43-45), this research being currently aimed to a targeted chemotherapy approach, such as with inhibitors of tyrosine kinase, since approximately $10 \%$ of patients with adenocarcinoma have the mutation for EGFR. Similarly, it was recently demonstrated in 43 patients with NSCLC that EUS-FNA lymph nodal samples are suitable for genetic research, and that in these cytological specimens it is possible to find the same genetic mutations in K-RAS, EGFR, BRAF and PIK3CA found from histological samples obtained from the primary tumour (46).

Therefore, minimally invasive techniques are now available, such as EBUS-TBNA and EUS-FNA being able to give in one time the diagnosis, the typing, staging, and genotyping of lung cancer with a single diagnostic procedure.

\section{EUS-FNA for the diagnosis of non-neoplastic dis- eases}

The reactive lymphadenopathy and granulomatous diseases (e.g. sarcoidosis, tuberculosis, histoplasmosis) are some of the benign diseases that might occur in the mediastinum, and that might be assesses by EUS investigation. Published studies have shown that EUS-FNA is in these situations an alternative non-invasive diagnostics.

The diagnosis of sarcoidosis is based on clinical suspicion and radiological, and histological confirmation of non-caseating granulomas, together with exclusion of other diseases with similar clinical and radiological presentation, such as tuberculosis and lymphoproliferative processes. Studies published in the recent years have shown that in patients with sarcoidosis EUS-FNA lymph node is a viable and safe procedure, with a diagnostic yield of $>82 \%$ for the identification of noncaseating granulomas (47-50). The diagnostic yield rises to $94 \%$ in stage I sarcoidosis when EUS- FNA needle aspirates are performed with a needle 19-gauge, rather than of 22-gauge (51), and the average sensitivity for the detection of granulomas is $87 \%$ with 22 gauge fine needle aspiration considering together both cytological samples and cell blocks, with a yield of $92 \%$ in stage I, and $77 \%$ in stage II, $33 \%$ of samples with a negative cytology but positive cell block (52), emphasizing the high diagnostic yield of EUS in stage I sarcoidosis. The number of recommended needle aspirations are equal to 4 for each lymph node (23).

In patients with mediastinal masses of unknown aetiology and no history of lung malignancy, sampling with EUS-FNA has shown in about $50 \%$ of cases a benign disease, such as benign lymphadenopathy, histoplasmosis, leiomyoma, sarcoidosis and teratoma (53). Tuberculosis is another granulomatous disease that most often comes in the differential diagnosis of sarcoidosis, and the sensitivity of the diagnostic methods varies depending on different endemicity of the disease. An Indian retrospective study was recently published, conducted in a tertiary care center in an area with a high prevalence of tuberculosis in 269 patients with mediastinal lymphadenopathy who underwent EUS-FNA (54). In 206 cases (76.5\%) a cytological diagnosis of granulomatous lymphadenitis was obtained, but only in $36.8 \%$ of cases it was possible to establish with certainty a diagnosis of tuberculosis (Ziehl Neelsen positive), while in only 7 cases (3.2\%) a definite diagnosis of sarcoidosis was possible, in the absence of a definitive typing of granulomatous lym- 
phadenitis in 123 cases $(60 \%)$. Thus, these results showed that in areas with a high prevalence of tuberculosis there is still a very high dilemma in the differential diagnostic between tuberculosis and sarcoidosis (54). Another recent Indian study, a prospective one, has evaluated 60 patients with mediastinal lymphadenopathy and suspected tuberculosis, in the absence of parenchymal lung lesions: EUS-FNA obtained a final diagnosis in 42 patients (32 tuberculosis, 6 sarcoidosis, and 4 Hodgkin's lymphoma) (54). Of the remaining 18 cases, 14 were nevertheless treated for tuberculosis based on clinical and cytological findings, while in 4 cases a mediastinoscopy was performed. The diagnostic accuracy, sensitivity and specificity of EUS-FNA in this study were respectively $93 \%, 71 \%$ and $100 \%$ (55).

\section{Complications}

Complications from EUS-FNA are very rare (about 1\%) (56), and include infection, bleeding, esophageal perforation and posterior pharyngeal, more frequent in

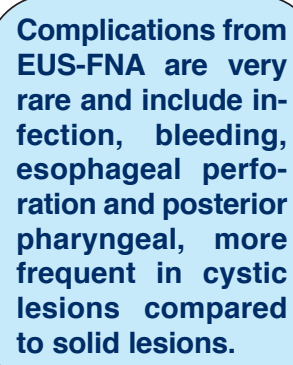

cystic lesions compared to solid lesions ( $14 \%$ vs $0.5 \%$ ) (57). The use of EUS-FNA needles of $19 \mathrm{G}, 22 \mathrm{G}$, and $25 \mathrm{G}$ shows a similar percentage of complications (56). The complications reported in the pulmonology case reports include rare cases of severe mediastinitis following sampling of benign cystic lesions $(24,25$, 58 ), and a recent case of mediastinum-esophageal fistula after-needle aspirate of a tuberculous lymphadenopathy (59).

\section{References}

1. DiMagno EP, Buxton JL, Regan PT, Hattery RR, Wilson DA, Suarez JR, Green PS. Ultrasonic endoscope. Lancet 1980;1(8169):629-31.

2. Pedersen $\mathrm{BH}$, Vilmann $\mathrm{P}$, Folke $\mathrm{K}$, Jacobsen GK, Krasnik M, Milman N, Hancke S. Endoscopic ultrasonography and real-time guided fine-needle aspiration biopsy of solid lesions of the mediastinum suspected of malignancy. Chest 1996;110(2):539-44.

3. Schmulewitz N, Wildi SM, Varadarajulu S, Roberts S, Hawes RH, Hoffman BJ, Durkalski V, Silvestri GA, Block MI, Reed C, Wallace MB. Accuracy of EUS criteria and primary tumor site for identification of mediastinal lymph node metastasis from non-small-cell lung cancer. Gastrointest Endosc 2004;59(2):205-12.

4. Toloza EM, Harpole L, McCrory DC. Noninvasive staging of non-small cell lung cancer: a review of the current evidence. Chest 2003;123(1 Suppl):137S$146 S$.

5. Vilmann P. Endoscopic ultrasonography-guided fineneedle aspiration biopsy of lymph nodes. Gastroin- test Endosc 1996;43(2 Pt 2):S24-9.

6. Rusch VW, Asamura H, Watanabe H, Giroux DJ, Rami-Porta R, Goldstraw P; Members of IASLC Staging Committee. The IASLC lung cancer staging project: a proposal for a new international lymph node map in the forthcoming seventh edition of the TNM classification for lung cancer. J Thorac Oncol 2009;4(5):568-77.

7. Tournoy KG, Annema JT, Krasnik M, Herth FJ, van Meerbeeck JP. Endoscopic and endobronchial ultrasonography according to the proposed lymph node map definition in the seventh edition of the tumor, node, metastasis classification for lung cancer. $J$ Thorac Oncol 2009;4(12):1576-84.

8. von Bartheld MB, Rabe KF, Annema JT. Transaortic EUS-guided FNA in the diagnosis of lung tumors and lymph nodes. Gastrointest Endosc 2009 Feb;69(2):345-9.

9. Tournoy KG, Praet MM, Van Maele G, Van Meerbeeck JP. Esophageal endoscopic ultrasound with fine-needle aspiration with an on-site cytopathologist: high accuracy for the diagnosis of mediastinal lymphadenopathy. Chest 2005;128(4):3004-9.

10. Silvestri GA, Gonzalez AV, Jantz MA, Margolis ML, Gould MK, Tanoue LT, Harris LJ, Detterbeck FC. Methods for staging non-small cell lung cancer: Diagnosis and management of lung cancer, 3rd edition: American College of Chest Physicians evidencebased clinical practice guidelines. Chest 2013 May;143(5 Suppl):e211S-50S.

11. Detterbeck FC, Jantz MA, Wallace M, Vansteenkiste J, Silvestri GA; American College of Chest Physicians. Invasive mediastinal staging of lung cancer: ACCP evidence-based clinical practice guidelines (2nd edition). Chest 2007;132(3 Suppl):202S-220S.

12. Annema JT, Rabe KF. Why respiratory physicians should learn and implement EUS-FNA. Am J Respir Crit Care Med 2007;176(1):99; author reply 99.

13. Annema JT, Bohoslavsky R, Burgers S, Smits M, Taal B, Venmans B, Nabers $\mathrm{H}$, van de Borne B, van Balkom R, Haitjema T, Welling A, Staaks G, Dekkers $\mathrm{OM}$, van Tinteren $\mathrm{H}$, Rabe KF. Implementation of endoscopic ultrasound for lung cancer staging. Gastrointest Endosc 2010;71(1):64-70.

14. Annema JT, Versteegh MI, Veseliç M, Voigt $P$, Rabe KF. Endoscopic ultrasound-guided fine-needle aspiration in the diagnosis and staging of lung cancer and its impact on surgical staging. J Clin Oncol 2005;23(33):8357-61.

15. Schuurbiers OC, Tournoy KG, Schoppers HJ, Dijkman BG, Timmers HJ, de Geus-Oei LF, Grefte JM, Rabe KF, Dekhuijzen PN, van der Heijden HF, Annema JT. EUS-FNA for the detection of left adrenal metastasis in patients with lung cancer. Lung Cancer 2011 Sep;73(3):310-5.

16. Varadarajulu $\mathrm{S}$, Hoffman $\mathrm{BJ}$, Hawes $\mathrm{RH}$, Eloubeidi MA. EUS-guided FNA of lung masses adjacent to or abutting the esophagus after unrevealing CT-guided biopsy or bronchoscopy. Gastrointest Endosc 2004;60(2):293-7.

17. Annema JT, Veseliç M, Rabe KF. EUS-guided FNA of centrally located lung tumours following a non-di- 
agnostic bronchoscopy. Lung Cancer 2005;48(3): 357-61; discussion 363-4.

18. Sawhney MS, Kratzke RA, Lederle FA, Holmstrom AM, Nelson DB, Kelly RF. EUS-guided FNA for the diagnosis of advanced lung cancer. Gastrointest Endosc 2006;63(7):959-65.

19. Mehra M, Tamhane A, Eloubeidi MA. EUS-guided FNA combined with flow cytometry in the diagnoses of suspected or recurrent intrathoracic or retroperitoneal lymphoma. Gastrointest Endosc 2005;62(4): 508-13.

20. Song HJ, Park YS, Seo DW, Jang SJ, Choi KD, Lee SS, Lee GH, Jung HY, Kim JH. Diagnosis of mediastinal tuberculosis by using EUS-guided needle sampling in a geographic region with an intermediate tuberculosis burden. Gastrointest Endosc 2010 Jun;71(7):1307-13.

21. Puri R, Vilmann P, Sud R, Kumar M, Taneja S, Verma $\mathrm{K}$, Kaushik N. Endoscopic ultrasound-guided fineneedle aspiration cytology in the evaluation of suspected tuberculosis in patients with isolated mediastinal lymphadenopathy. Endoscopy 2010 Jun;42(6): 462-7.

22. Manucha V, Kaur G, Verma K. Endoscopic ultrasound-guided fine needle aspiration (EUS-FNA) of mediastinal lymph nodes: Experience from region with high prevalence of tuberculosis. Diagn Cytopathol 2011 Apr 28. doi: 10.1002/dc.21698.

23. von Bartheld MB, Veseliç-Charvat M, Rabe KF, Annema JT. Endoscopic ultrasound-guided fine-needle aspiration for the diagnosis of sarcoidosis. Endoscopy 2010;42(3):213-7.

24. Wildi SM, Hoda RS, Fickling W, Schmulewitz N, Varadarajulu S, Roberts SS, Ferguson B, Hoffman BJ, Hawes RH, Wallace MB. Diagnosis of benign cysts of the mediastinum: the role and risks of EUS and FNA. Gastrointest Endosc 2003;58(3):362-8.

25. Annema JT, Veseliç M, Versteegh MI, Rabe KF. Mediastinitis caused by EUS-FNA of a bronchogenic cyst. Endoscopy 2003;35(9):791-3.

26. Micames CG, McCrory DC, Pavey DA, Jowell PS, Gress FG. Endoscopic ultrasound-guided fine-needle aspiration for non-small cell lung cancer staging: A systematic review and metaanalysis. Chest 2007;131(2):539-48.

27. Annema JT, Versteegh MI, Veseliç M, Welker L, Mauad T, Sont JK, Willems LN, Rabe KF. Endoscopic ultrasound added to mediastinoscopy for preoperative staging of patients with lung cancer. JAMA 2005;294(8):931-6.

28. Tournoy KG, De Ryck F, Vanwalleghem LR, Vermassen F, Praet M, Aerts JG, Van Maele G, van Meerbeeck JP. Endoscopic ultrasound reduces surgical mediastinal staging in lung cancer: a randomized trial. Am J Respir Crit Care Med 2008 Mar $1 ; 177(5): 531-5$.

29. Annema JT, van Meerbeeck JP, Rintoul RC, Dooms C, Deschepper E, Dekkers OM, De Leyn P, Braun J, Carroll NR, Praet M, de Ryck F, Vansteenkiste J, Vermassen F, Versteegh MI, Veseliç M, Nicholson AG, Rabe KF, Tournoy KG. Mediastinoscopy vs endosonography for mediastinal nodal staging of lung cancer: a randomized trial. JAMA 2010;304(20): 2245-52.

30. Wallace MB, Ravenel J, Block MI, Fraig M, Silvestri G, Wildi S, Schmulewitz N, Varadarajulu S, Roberts S, Hoffman BJ, Hawes RH, Reed CE. Endoscopic ultrasound in lung cancer patients with a normal mediastinum on computed tomography. Ann Thorac Surg 2004;77(5):1763-8.

31. LeBlanc JK, Devereaux BM, Imperiale TF, Kesler K, DeWitt JM, Cummings O, Ciaccia D, Sherman S, Mathur P, Conces D, Brooks J, Chriswell M, Einhorn L, Collins E. Endoscopic ultrasound in non-small cell lung cancer and negative mediastinum on computed tomography. Am J Respir Crit Care Med 2005 Jan 15;171(2):177-82.

32. von Bartheld MB, Versteegh MI, Braun J, Willems LN, Rabe KF, Annema JT. Transesophageal ultrasound-guided fine-needle aspiration for the mediastinal restaging of non-small cell lung cancer. $\mathrm{J}$ Thorac Oncol 2011;6(9):1510-5.

33. Annema JT, Veseliç M, Versteegh MI, Willems LN, Rabe KF. Mediastinal restaging: EUS-FNA offers a new perspective. Lung Cancer 2003;42(3):311-8.

34. Arroliga AC, Matthay RA. The role of bronchoscopy in lung cancer. Clin Chest Med 1993;14(1):87-98.

35. Salazar AM, Westcott JL. The role of transthoracic needle biopsy for the diagnosis and staging of lung cancer. Clin Chest Med 1993;14(1):99-110.

36. Kazerooni EA, Lim FT, Mikhail A, Martinez FJ. Risk of pneumothorax in CT-guided transthoracic needle aspiration biopsy of the lung. Radiology 1996;198(2): 371-5.

37. Sawhney MS, Kratzke RA, Lederle FA, Holmstrom AM, Nelson DB, Kelly RF. EUS-guided FNA for the diagnosis of advanced lung cancer. Gastrointest Endosc 2006;63(7):959-65.

38. Witte B, Neumeister W, Huertgen M. Does endoesophageal ultrasound-guided fine-needle aspiration replace mediastinoscopy in mediastinal staging of thoracic malignancies? Eur J Cardiothorac Surg 2008;33(6):1124-8.

39. Gupta NC, Graeber GM, Tamim WJ, Rogers JS, Irisari L, Bishop HA. Clinical utility of PET-FDG imaging in differentiation of benign from malignant adrenal masses in lung cancer. Clin Lung Cancer 2001;3(1): 59-64.

40. Stelow EB, Debol SM, Stanley MW, Mallery S, Lai R, Bardales RH. Sampling of the adrenal glands by endoscopic ultrasound-guided fine-needle aspiration. Diagn Cytopathol 2005;33(1):26-30.

41. Schuurbiers OC, Tournoy KG, Schoppers HJ, Dijkman BG, Timmers HJ, de Geus-Oei LF, Grefte JM, Rabe KF, Dekhuijzen PN, van der Heijden HF, Annema JT. EUS-FNA for the detection of left adrenal metastasis in patients with lung cancer. Lung Cancer $2011 ; 73(3): 310-5$

42. Haseganu LE, Diehl DL. Left adrenal gland hemorrhage as a complication of EUS-FNA. Gastrointest Endosc 2009;69(6):e51-2.

43. Garcia-Olivé I, Monsó E, Andreo F, Sanz-Santos J, Taron M, Molina-Vila MA, Llatjós M, Castellà E, Moran T, Bertran-Alamillo J, Mayo-de-Las-Casas 
C, Queralt C, Rosell R. Endobronchial ultrasoundguided transbronchial needle aspiration for identifying EGFR mutations. Eur Respir J 2010;35 (2):391-5.

44. Schuurbiers OC, Looijen-Salamon MG, Ligtenberg MJ, van der Heijden HF. A brief retrospective report on the feasibility of epidermal growth factor receptor and KRAS mutation analysis in transesophageal ultrasound- and endobronchial ultrasound-guided fine needle cytological aspirates. J Thorac Oncol 2010 Oct;5(10):1664-7.

45. Ulivi P, Romagnoli M, Chiodini E, Casoni GL, Capelli L, Gurioli C, Zoli W, Saragoni L, Dubini A, Tesei A, Amadori D, Poletti V. Assessment of EGFR and K-ras mutations in Fixed and Fresh Specimens from Transesophageal Ultrasound-Guided Fine Needle Aspiration (EUS-FNA) in Non-Small-Cell Lung Cancer (NSCLC) patients. Intern J Oncol 2012;41:147-152.

46. van Eijk R, Licht J, Schrumpf M, Talebian Yazdi M, Ruano D, Forte GI, Nederlof PM, Veselic M, Rabe KF, Annema JT, Smit V, Morreau H, van Wezel T. Rapid KRAS, EGFR, BRAF and PIK3CA mutation analysis of fine needle aspirates from non-small-cell lung cancer using allele-specific qPCR. PLoS One 2011 Mar 8;6(3):e17791.

47. Annema JT, Veseliç M, Rabe KF. Endoscopic ultrasound-guided fine-needle aspiration for the diagnosis of sarcoidosis. Eur Respir J 2005;25(3):405-9.

48. Fritscher-Ravens A, Sriram PV, Topalidis T, Hauber HP, Meyer A, Soehendra N, Pforte A. Diagnosing sarcoidosis using endosonography-guided fine-needle aspiration. Chest 2000;118(4):928-35.

49. Michael H, Ho S, Pollack B, Gupta M, Gress F. Diagnosis of intra-abdominal and mediastinal sarcoidosis with EUS-guided FNA. Gastrointest Endosc 2008;67(1):28-34.

50. Wildi SM, Judson MA, Fraig M, Fickling WE, Schmulewitz N, Varadarajulu S, Roberts SS, Prasad $\mathrm{P}$, Hawes $\mathrm{RH}$, Wallace MB, Hoffman BJ. Is endosonography guided fine needle aspiration (EUSFNA) for sarcoidosis as good as we think? Thorax 2004;59(9):794-9.

51. Iwashita T, Yasuda I, Doi S, Kato T, Sano K, Yasuda S, Nakashima M, Hirose Y, Takaimi T, Moriwaki H. The yield of endoscopic ultrasound-guided fine nee- dle aspiration for histological diagnosis in patients suspected of stage I sarcoidosis. Endoscopy 2008;40(5):400-5.

52. von Bartheld MB, Veseliç-Charvat M, Rabe KF, Annema JT. Endoscopic ultrasound-guided fine-needle aspiration for the diagnosis of sarcoidosis. Endoscopy 2010;42(3):213-7.

53. Devereaux BM, Leblanc JK, Yousif E, Kesler K, Brooks J, Mathur P, Sandler A, Chappo J, Lehman GA, Sherman S, Gress F, Ciaccia D. Clinical utility of EUS-guided fine-needle aspiration of mediastinal masses in the absence of known pulmonary malignancy. Gastrointest Endosc 2002;56(3):397-401.

54. Manucha V, Kaur G, Verma K. Endoscopic ultrasound-guided fine needle aspiration (EUS-FNA) of mediastinal lymph nodes: Experience from region with high prevalence of tuberculosis. Diagn Cytopathol 2011 Apr 28. doi: 10.1002/dc.21698.

55. Puri R, Vilmann P, Sud R, Kumar M, Taneja S, Verma K, Kaushik N. Endoscopic ultrasound-guided fineneedle aspiration cytology in the evaluation of suspected tuberculosis in patients with isolated mediastinal lymphadenopathy. Endoscopy 2010;42(6):462-7.

56. Polkowski M, Larghi A, Weynand B, Boustière C, Giovannini M, Pujol B, Dumonceau JM; European Society of Gastrointestinal Endoscopy (ESGE). Learning, techniques, and complications of endoscopic ultrasound (EUS)-guided sampling in gastroenterology: European Society of Gastrointestinal Endoscopy (ESGE) Technical Guideline. Endoscopy 2012;44(2):190-206.

57. Wiersema MJ, Vilmann P, Giovannini M, Chang KJ, Wiersema LM. Endosonography-guided fine-needle aspiration biopsy: diagnostic accuracy and complication assessment. Gastroenterology 1997;112(4): 1087-95.

58. Ryan AG, Zamvar V, Roberts SA. latrogenic candidal infection of a mediastinal foregut cyst following endoscopic ultrasound-guided fine-needle aspiration. Endoscopy 2002;34(10):838-9.

59. von Bartheld MB, van Kralingen KW, Veenendaal RA, Willems LN, Rabe KF, Annema JT. Mediastinalesophageal fistulae after EUS-FNA of tuberculosis of the mediastinum. Gastrointest Endosc 2010;71 (1):210-2. 